Carbohydrate Polymers

Elsevier Editorial system(tm) for

Manuscript Draft

Manuscript Number: CARBPOL-D-15-02918

Title: New Insights into Xanthan Synergistic Interactions with Konjac glucomannan: A Novel Interaction Mechanism proposal

Article Type: Research Paper

Keywords: Xanthan; Konjac mannan; Helix, Random Coil, Models of Interaction

Corresponding Author: Mr. Amir Abbaszadeh,

Corresponding Author's Institution:

First Author: Amir Abbaszadeh

Order of Authors: Amir Abbaszadeh; Bill Macnaughtan; Graham Sworn; Tim Foster

Abstract: The interactions of xanthans containing precise acetate and pyruvate concentration with Konjac glucomannan (KGM) were studied at different sodium chloride and polymer concentrations. A new unified model of the interaction is proposed, taking into account previous models in the literature. This study suggests that the interactions occur by two distinct mechanisms dependent on xanthan conformation. These interactions are not mutually exclusive and may co-exist and hence produce complicated traces. Consequently two types of gel which melt at different temperature ranges can be formed. Depending on the xanthan helix coil transition temperature, one or both of the synergistic states may exist in the hydrocolloid blend. The proposed model has been tested rheologically and using Differential Scanning Calorimetry by varying salt concentration and using samples containing different functional group concentrations.

Suggested Reviewers: John Mitchell

Bioscience, Nottingham Uni

john.mitchell@nottingham.ac.uk

Prof J Mitchell has published many papers in the field of hydrocolloids and is a recognised expert in the area of carbohydrates.

Stephen Harding

Bioscience, Nottingham Uni

steve.harding@nottingham.ac.uk

Prof $S$ Harding has a wide knowledge of physical methods as applied to structure in the field of carbohydrates and proteins.

Peter Williams

Bioscience, Glyndwr Uni

p.a.williams@glyndwr.ac.uk

Prof P Williams has published detailed work on the physical properties of carbohydrate solutions particularly related to gelling and viscosity. 

Dr A Abbaszadeh

Food Sciences Division

Sutton Bonington campus

Leicestershire, UK

LE12 5RD

$18 / 09 / 2015$

To the acting editor

Dear Sir,

We ask you to consider for publication in Carbohydrate Polymers, our manuscript entitled "New Insights into Xanthan Synergistic Interactions with Konjac Glucomannan: A New Interaction Mechanism Proposal" by A. Abbaszadeh, W. MacNaughtan, G. Sworn and T.J. Foster.

We believe this manuscript unifies the various approaches to and models of the interactions between these biopolymers which have been reported extensively over the last few decades. The work has the clear objective of providing a fundamental understanding of the gelation of mixtures of these biopolymers and reaches some definitive conclusions. We believe the clarity of the approach and the rationalisation of apparently disparate previous models merits publication in a high quality journal such as Carbohydrate Polymers.

This work is an original contribution by the authors and has not been published previously nor is under consideration by any other journal at the present time. The publication of this work is approved by all the authors. All ideas and work taken from the literature have been appropriately referenced.

In accordance with your requirements we offer the names, affiliations and E-mail addresses of the following 5 referees who are fit to judge the merits of the work:

1) Prof. S Harding

2) Prof V Morris

3) Prof Ed Morris

4) Prof John Mitcell

5) Prof Thomas Heinze 
Yours,

Amir Abbaszadeh 
We believe this manuscript unifies the various approaches to and models of the interactions between these biopolymers which have been reported extensively over the last few decades.

The work has the clear objective of providing a fundamental understanding of the gelation of mixtures of these biopolymers and reaches some definitive conclusions. 


\section{New Insights into Xanthan Synergistic Interactions with Konjac}

3 glucomannan: A Novel Interaction Mechanism proposal

4 A. Abbaszadeh ${ }^{1 *}$, W. MacNaughtan ${ }^{1}$, G. Sworn ${ }^{2}$ and T.J. Foster ${ }^{1}$

5

6 'Division of Food Sciences, School of Biosciences, University of Nottingham, Sutton Bonington Campus, 7 Loughborough, LE12 5RD, UK.

8 Member of the European Polysaccharide Network of Excellence (EPNOE).

$9{ }^{2}$ DuPont, Danisco France SAS, 20 rue Brunel, 75017 Paris, France.

Keywords: Xanthan; Konjac mannan; Helix, Random Coil, Models of Interaction 


\section{Abstract}

3 The interactions of xanthans containing precise acetate and pyruvate concentration with Konjac glucomannan (KGM)

4 were studied at different sodium chloride and polymer concentrations. A new unified model of the interaction is

5 proposed, taking into account previous models in the literature. This study suggests that the interactions occur by two

6 distinct mechanisms dependent on xanthan conformation. These interactions are not mutually exclusive and may co-

7 exist and hence produce complicated traces. Consequently two types of gel which melt at different temperature ranges

8 can be formed. Depending on the xanthan helix coil transition temperature, one or both of the synergistic states may

9 exist in the hydrocolloid blend. The proposed model has been tested rheologically and using Differential Scanning

10 Calorimetry by varying salt concentration and using samples containing different functional group concentrations. 
Mixed polysaccharide gels are a current active area of research. Methods continue to be improved to control and describe the mechanism of interaction and the properties of mixed gels.

One polysaccharide which is well-known for gelation dependent on synergistic interaction with mannan based gums, is xanthan. Xanthan gum is an extracellular polysaccharide used as a food additive and rheological modifier, however it does not form true gels on its own ${ }^{1}$. Xanthan forms self-supporting gels in mixtures with galactomannans of low galactose content, such as locust bean gum, or with konjac glucomannan (KGM). Similar to xanthan, these polysaccharides have a $\beta-(1 \rightarrow 4)$ linkage linear backbone.

There are many hypotheses concerning the mechanism of gelation between xanthan and galacto- and glucomannans. One of the earliest proposed mechanisms ${ }^{2,3}$ was that the unsubstituted regions of the mannan backbone attach to the surface of the xanthan helix, i.e. interaction occurs when xanthan is in the ordered conformation. This hypothesis has been supported by further work ${ }^{4-7}$.

In a different approach, other studies ${ }^{8-10}$ have suggested the possibility of interaction between the side chains of xanthan and unsubstituted segments of the backbone of the mannan polysaccharide.

However, it has also been suggested that the gel formation is due to intermolecular binding between the galacto/glucomannan and the disordered backbone of the xanthan molecule, rather than to the 5 -fold helix surface ${ }^{11-}$

However, as interactions are known to occur at room temperature i.e. well below the transition temperature $\left(\mathrm{T}_{\mathrm{m}}\right)$ and when xanthan is in the helical conformation, it has been suggested that low amounts of the disordered form may exist among the ordered chains making the interaction with the disordered form possible at room temperature ${ }^{4,7}$. In this hypothesis the xanthan order-disorder transition is an equilibrium process occurring over a significant range of temperature, and the level of disordered xanthan will depend on the temperature of the xanthan sample relative to $T_{m}$ ${ }^{17}$. Conversely, another possibility is that small amounts of the ordered form will exist among disordered chains for interactions at high temperature ${ }^{5,18-20}$. In a contemporary study Foster and Morris ${ }^{21}$ suggested that if the xanthan molecule is ordered at the time of mixing, the conformation will be forced into a geometry required for efficient binding with the co-synergist; if it is disordered, the same heterotypic structure will be formed directly, as this is enthalpically more favourable than interaction with the normal 5-fold helix.

A final hypothesis suggests that either ordered or disordered segments may participate in interactions with galacto and glucomannans ${ }^{4,22-25}$. Williams et. al. (1991) ${ }^{22}$ suggested that in the absence of electrolyte konjac glucomannan interacts with disordered xanthan chains whilst in the presence of $40 \mathrm{mM} \mathrm{NaCl}$, it interacts with ordered xanthan chains. However, Mannion's work ${ }^{4}$ proposed that xanthan and galactomannans may interact by two distinct mechanisms. The first requires heating of the mixture to within $70^{\circ} \mathrm{C}$ of the $\mathrm{T}_{\mathrm{m}}$ of xanthan, giving higher storage moduli dependent on the galactose content of the galactomannan. The second mechanism takes place at room temperature and gives weaker, more flexible gels, whose rheological properties do not depend on galactose content, and in which the xanthan helix is retained in the post-interaction complex. Lundin et al. (1994) ${ }^{23}$ also suggested that galactomannan with a low Mannose/Galactose (M/G) ratio is excluded from the xanthan aggregates and can only bind to the surface of the xanthan superstrands, however, galactomannan with a high Mannose/Galactose ratio has a greater tendency to interact, and is, therefore, able to bind to the xanthan helix as well as to the surface of the xanthan superstrands. Similarly, Rinaudo et al. (1999) ${ }^{24}$ reported that for low galactose contents (M/G > 3) interactions occured at temperatures higher than $45^{\circ} \mathrm{C}$. The existence of these interactions does not depend on the ionic concentration of the solutions and seems to involve xanthan chains in their ordered as well as in their disordered conformations. For lower M/G values, interactions appear at lower temperatures but, in this case, only disordered xanthan chains can interact with these galactomannans. As the amount of disordered xanthan chains depends on the total ionic concentration, which determines the helix-coil transition temperature, these interactions depend strongly on the external salt concentration. Goycoolea et. al. (2001) ${ }^{25}$ reported that for high M/G values, only low temperature interactions occur and galactomannan can also interact via the galactose branches rather than the backbone.

Clearly then, although the interactions between xanthan and galacto and glucomannans have been investigated over the past four decades, there is still controversy concerning the mechanism of gelation. The aim of this work is to attain a better understanding of the interaction mechanism between xanthan and KGM, by studying xanthans having different but well defined levels of acetate and pyruvate, and changing polymer and sodium chloride concentrations in order to manipulate the xanthan transition temperature and test its relevance to the mechanism of synergistic interaction. In future work we intend to describe the interaction between galactomannans such as locust bean gum and xanthan, however in the present work we have chosen to study konjac glucomannan in some detail, as this polymer exhibits less variability in structure due to the absence of sidechains. 


\section{MATERIALS AND METHODS}

A range of xanthan samples having variable pyruvate and acetate contents (see Table 1) were kindly provided by DuPont. Glucomannan (KGM) was supplied by Shimizu Chemical Corporation. Sodium azide was supplied by Acros organic, Geel Belgium and used as a bactericide at a concentration of $0.05 \%$ in all samples. Sodium chloride was obtained from Fisher Scientific UK Ltd. Loughborough, UK.

\section{Manufacture of xanthans}

The method of producing xanthans of different contents of pyruvate was as follows. The SASP and SAHP samples were a result of natural variations in the concentration of the functional groups produced during the fermentation process by Xanthomonas Campestris. Medium and high pyruvate batches were then selected from the available range of concentrations. The low pyruvate content of the SALP sample was produced by subjecting the fermentation broth to heat treatment in acidic conditions. The method of producing xanthans of different contents of acetate was based upon heat treatment under alkaline conditions of xanthan with naturally occurring high acetate levels ${ }^{26}$.

\section{Preparation of solutions}

Solutions were prepared by cold dispersion of the polymers in distilled water. Samples of one polymer were then mixed using a magnetic flea whilst heating to $90{ }^{\circ} \mathrm{C}$ and held at that temperature for $20 \mathrm{~min}$. Upon cooling to room temperature individual polymer samples were mixed together in a ratio of 1:1 and left over night.

\section{High Sensitivity Differential Scanning Calorimetry (DSC)}

Experiments were performed in a Setaram Micro DSC III (Setaram, Caluire, France) using cells made from Hastelloy, capable of holding approximately $0.8 \mathrm{ml}$ and sealed using Hastelloy screw tops with viton "O" rings. Solutions were placed with the minimum of disturbance of the viscous structure into the cell and initially cooled to a starting temperature of $10{ }^{\circ} \mathrm{C}$. Samples were heated and cooled at rates of $1^{\circ} \mathrm{C} \min ^{-1}$. from 10 to $100^{\circ} \mathrm{C}$. Normally 2 complete heating and cooling cycles were run. The reference cell was filled with water and matched for overall heat capacity with the sample. This ensured that the calorimeter was balanced and that the heat flow signal was centred at approximately the zero level which gave the most sensitive result.

\section{Small deformation mechanical spetroscopy}

Rheological testing of the solutions and gels was performed in oscillation using cone and plate geometry $(4 \mathrm{~cm}$ diameter; $1.581^{\circ}$ cone angle) with an Anton Paar Physica MCR-301 rheometer. Samples were loaded with minimal disturbance at room temperature, coated around the periphery of the sample with light silicone oil to minimise the loss of water, and left unperturbed for $30 \mathrm{~min}$ before measurements were made. A temperature sweep was obtained by heating at $1{ }^{\circ} \mathrm{C} \mathrm{min}-1$ and measurements made at a frequency of $1 \mathrm{~Hz}$ and a strain of $0.5 \%$. This ensured that data was obtained in the linear viscoelastic region.

\section{RESULTS AND DISCUSSION}

The influence of salt, acetate and pyruvate content on the xanthan transition temperature and the interaction with KGM

Konjac glucomannan (KGM) at low ionic strengths is known to form a gel after mixing with xanthan ${ }^{5,27}$ and shows a limited interaction with stable xanthan helices ${ }^{21}$. Figure 1 and 2 show DSC second heats of different types of xanthan, individually and in mixtures with KGM at a total concentration of $0.5 \%$ wt. Goycoolea et al. (1995) ${ }^{20}$ studied the stoichiometry of mixtures of xanthan-KGM and discovered a 1:1 mix was optimal, which is the ratio used in this study. The mix of SA/SP-KGM shows the previously seen endotherm by Annable et al. (1994) ${ }^{5}$ using DSC. The wide and biphasic helix-coil transition (Figure 1a) for SA/SP $\left(48^{\circ} \mathrm{C}\right.$ to $80^{\circ} \mathrm{C}$; enthalpy $=6.2 \mathrm{~J} / \mathrm{g}$ ) has changed to a narrower single peak transition $\left(52^{\circ} \mathrm{C}\right.$ to $67^{\circ} \mathrm{C}$ enthalpy $=5.2 \mathrm{~J} / \mathrm{g} ; 10.4 \mathrm{~J} / \mathrm{g}$ if we assume all the heat is due to the xanthan) after mixing with KGM. The SA/HP and LA/HP samples, in which the $\mathrm{T}_{\mathrm{m}}$ for xanthan alone was approximately $52^{\circ} \mathrm{C}$ and $43^{\circ} \mathrm{C}$ respectively, form a new endothermic peak with almost the same temperature range and enthalpy as the SA/SP sample in combination with KGM and the xanthan transition peak disappears (Figure 1b and c).

The SA/LP xanthan shows a different trend (Figure 2a). The xanthan transition, at high temperature, remains detectable when combined with $\mathrm{KGM}$, however a smaller endotherm in the region of $40^{\circ} \mathrm{C}$ represents the synergistic interaction. This kind of transition has been reported previously by Annable et al. (1994) ${ }^{5}$ at an ionic strength of $40 \mathrm{mM} \mathrm{NaCl}$ rather than $10 \mathrm{mM} \mathrm{NaCl}$. By increasing the ionic strength to $40 \mathrm{mM} \mathrm{NaCl}$ (Figure $2 \mathrm{~b}$ ), the SA/HP sample now shows a similar trend to the SA/LP sample at the lower ionic strength of $10 \mathrm{mM} \mathrm{NaCl}$, with a synergistic peak in the region of $40-58^{\circ} \mathrm{C}$, slightly higher than the SA/LP synergistic peak,and a separate, discernible xanthan helix-coil transition. 


\section{The effect of xanthan helical stability on the interaction}

The synergistic peak at around $40^{\circ} \mathrm{C}$ is also detectable for the most stable of the samples, SA/VLP (Figure2c), which indicates that the existence of the terminal mannose alone is enough to produce the low temperature synergistic junction zone. However, Foster and Morris ${ }^{21}$ did not find a synergistic peak for the polytetramer and attributed this to the enthalpic stability of the polytetramer helix $(\Delta \mathrm{H} \simeq 8.5 \mathrm{~J} / \mathrm{g})$. The similarity of the enthalpy of transition for SA/VLP $(\Delta \mathrm{H} \simeq 8.4 \mathrm{~J} / \mathrm{g})$ which does show the synergistic peak and the polytetramer may indicate a different reason, probably structural, for the lack of synergistic interaction between polytetramer and KGM. The present results (Figure 2) indicate that even though the xanthan helix-coil transition temperatures almost matched by changing sodium chloride concentration, the destabilising effect of pyruvate on the helical compactness produces higher temperature melting i.e. more stable synergistic gels. As is shown in Figure $2 \mathrm{a}$ and $\mathrm{b}$ and $\mathrm{c}$ by increasing the pyruvate content respectively in SA/VLP, SA/LP and SA/HP samples, the temperature of synergistic gelation $\left(\mathrm{T}_{\text {gel }}\right)$ is increased from $41{ }^{\circ} \mathrm{C}$ for $\mathrm{SA} / \mathrm{VLP}$ to $43^{\circ} \mathrm{C}$ for $\mathrm{SA} / \mathrm{LP}$ and $49^{\circ} \mathrm{C}$ for $\mathrm{SA} / \mathrm{HP}$.

Recently Fitzpatrick et al. (2012) ${ }^{18}$ emphasized that the interaction between xanthan and KGM in mixed gels occurs only if the xanthan molecules are in the ordered helical form. However as can be seen in Figure 3 upon cooling the exothermic peak of the disorder-order transition of VLA/HP xanthan alone occurs at a low temperature, below $\sim 40^{\circ} \mathrm{C}$ compared with the synergistic exotherm $\left(\sim 60^{\circ} \mathrm{C}\right)$ i.e. xanthan is obviously in a disordered conformation when interaction occurs at temperatures above the onset of xanthan helix formation.

\section{The combination of DSC and rheology data}

Figure 4a shows combined DSC and rheology traces for the same xanthan/KGM mixture at a total polymer concentration of $1 \mathrm{wt} \%$. The high and low pyruvylated samples show a similar trend to that seen for the lower concentration samples $(0.5 \mathrm{wt} \%$.) using both DSC and rheology, i.e. for a high pyruvylated sample after mixing with $\mathrm{KGM}$ the xanthan transition peak is replaced with a new peak at around $60^{\circ} \mathrm{C}$ and for a low pyruvylated sample the xanthan transition, at high temperature, remains detectable by DSC when combined with KGM, however a smaller endotherm in the region of $40^{\circ} \mathrm{C}$ represents the synergistic interaction.

The rheometry data on Figure 4 shows the elastic modulus $\left(G^{\prime}\right)$ on second heating as a function of temperature with the $\mathrm{Y}$-axis shifted to aid comparison. The onset temperatures for the synergistic endothermic DSC peaks are mirrored by the temperatures at which the onset of gel melting is seen. Interestingly, at a higher concentration of the SA/SP sample, the broad transition endothermic peak from $59^{\circ} \mathrm{C}$ to $84^{\circ} \mathrm{C}$ at $1 \%$ wt and $10 \mathrm{mM} \mathrm{NaCl}$ is replaced with two smaller peaks at around $60^{\circ} \mathrm{C}$ and $40^{\circ} \mathrm{C}$ after mixing with KGM (Figure 4a). Figure $4 \mathrm{~b}$ shows DSC and rheology data for samples mixed with $\mathrm{KGM}$ but at $40 \mathrm{mM} \mathrm{NaCl}$, again at a concentration of $1 \%$ wt. As expected, by increasing the ionic strength the xanthan helix-coil transition temperature is increased for all of the samples. For the high pyruvylated sample $\mathrm{SA} / \mathrm{HP}$ at $40 \mathrm{mM} \mathrm{NaCl}$, the $60^{\circ} \mathrm{C}$ synergistic peak seen at $10 \mathrm{mM} \mathrm{NaCl}$ is replaced with a new peak in the region of $40-50^{\circ} \mathrm{C}$, slightly higher than the SA/LP synergistic peak, and a still visible xanthan helix-coil transition. For the SA/SP-KGM mixture at $40 \mathrm{mM} \mathrm{NaCl}$, the xanthan $\mathrm{T}_{\mathrm{m}}$ increased to $\sim 90^{\circ} \mathrm{C}$ and the $60^{\circ} \mathrm{C}$ endotherm disappeared, however the $40-50^{\circ} \mathrm{C}$ endotherm was detectable. For the SA/LP-KGM mixture the xanthan $\mathrm{T}_{\mathrm{m}}$ increased to $\sim 94^{\circ} \mathrm{C}$ but temperature of gelation $\left(\mathrm{T}_{\text {gel }}\right)$ remained detectable at $40^{\circ} \mathrm{C}$.

The synergistic endothermic peak onset temperatures observed by DSC are commensurate with the temperatures at which the onset of gel melting is measured by rheology. These effects have previously been reported as the effect of salt in decreasing the $\mathrm{T}_{\mathrm{gel}}$; the temperature of interaction ${ }^{5}$. The more stable the xanthan helix, produced by higher salt contents or lower pyruvate levels, the more limited the interactions which occur with co-synergists ${ }^{21}$.

\section{A more detailed consideration of the nature of the interaction}

Two types of mechanism are proposed, supported by evidence showing the binding of xanthan to KGM from rheology and DSC data. By taking into account previously proposed models and utilising a range of proprietary xanthans with known molecular structure, a unified model for the interaction of xanthan and co-synergist has been proposed. According to this model xanthan interacts with KGM at room temperature by two mechanisms (Type A and Type B) (cf. Mannion et al., 1992 and Fitzsimons et al., 2008) ${ }^{4,7}$. This can occur simultaneously and form gels which melt in two temperature ranges. The mechanisms are discussed below.

\section{The storage modulus and the temperature of gelation}

Figure 5 shows the elastic modulus $\left(\mathrm{G}^{\prime}\right)$ as a function of temperature whilst cooling at a rate of $1^{\circ} \mathrm{Cmin}^{-1}$ for xanthan-KGM mixtures at a total polymer concentration of $0.5 \% \mathrm{w} / \mathrm{w}$. For the highly pyruvylated xanthan samples $\mathrm{SA} / \mathrm{HP}$ and LA/HP, G' starts to increase sharply below about $60^{\circ} \mathrm{C}$ independent of acetate level. By increasing the ionic strength to $40 \mathrm{mM} \mathrm{NaCl}$, the $\mathrm{SA} / \mathrm{HP}$ sample shows a consequent reduction in $\mathrm{T}_{\text {gel }}$ to $\sim 50^{\circ} \mathrm{C}$, commensurate with 
the endotherm shown in Figure $4 \mathrm{~b}$. The $\mathrm{T}_{\mathrm{gel}}$ for $\mathrm{SA} / \mathrm{LP}$ at $10 \mathrm{mM} \mathrm{NaCl}$ also matched the temperature of the endotherm seen in Figures 2a and 4a. The HP synergistic gels show higher final elastic moduli at $20^{\circ} \mathrm{C}$, indicating that either there are more junction zones in the gel formed at $60^{\circ} \mathrm{C}$, when the xanthan is still disordered, or the homotypic xanthan-xanthan interactions are enhanced in the HP samples (data not shown) and play an important role in stabilising the synergistic gel. Given there is no indication of the individual xanthan transition $<60^{\circ} \mathrm{C}$ in these mixtures and the fact that the mixed gel stoichiometry corresponds with such mixing ratios, this argues against the latter assumption, and suggests all xanthan molecules are occupied in the synergistic interactions.

\section{The relevance of the xanthan transition temperature}

As has been indicated already, the SA/SP xanthan sample, which exhibits a broad DSC peak for xanthan alone at $10 \mathrm{mM} \mathrm{NaCl}$, shows two waves of G' increase when mixed with KGM (Figure 4a); one starting around $60^{\circ} \mathrm{C}$ similar to that seen for samples containing high pyruvate levels and low ionic strength and another one about $45^{\circ} \mathrm{C}$, in the same region as that for $\mathrm{SA} / \mathrm{HP}$ at $40 \mathrm{mM} \mathrm{NaCl}$, which suggests a different mechanism for its interaction with $\mathrm{KGM}$. As has been shown on Figure 1a, the broad exotherm of the coil-helix transition for SA/SP occurs over a wide range centred around $60^{\circ} \mathrm{C}$, where gelation is seen for the HP xanthans. Therefore, at the point of the first wave of $\mathrm{G}^{\prime}$ increase $\left(60^{\circ} \mathrm{C}\right)$ some of the xanthan molecules are ordered, with approximately $50 \%$ of the transition still to take place. The two waves of $G^{\prime}$ increase therefore indicate two different modes of xanthan-KGM interaction within one mixture. These mechanisms are described in the following discussion.

\section{Type A and Type B interaction}

In the Type A interaction, xanthan retains its helical conformation when interacting with KGM and the gel melts at a lower temperature, $\sim 30-45^{\circ} \mathrm{C}$. In the Type $\mathrm{B}$ interaction, the 2 -fold conformation of disordered xanthan is responsible for the synergistic binding with KGM. The possibility of this transition has been shown by computer simulation ${ }^{28,29}$. The interaction occurs via backbone-to-backbone formation of junction zones and the formed gel melts at the higher temperature of $\sim 60^{\circ} \mathrm{C}$. The Type B interaction can start with both ordered and disordered xanthan conformations. If xanthan is in the disordered conformation just before the synergistic interaction, for example the VLA/HP sample at low ionic strength, direct binding (backbone-to-backbone) occurs with KGM, however, if the xanthan molecule is ordered such as in the SA/LP sample, a type A interaction is expected. The SA/SP sample at $10 \mathrm{mM} \mathrm{NaCl}$ has a xanthan coil-helix transition with a mid-point around 60C therefore for this xanthan both Types of interaction, $\mathrm{A}$ and $\mathrm{B}$ occur.

\section{Charge effects}

Agoub et al. (2007) ${ }^{30}$ reported that a progressive reduction in $\mathrm{pH}$ raises the temperature of the xanthan disorderorder transition as measured by DSC, and decreases the gelation temperature of xanthan/KGM mixtures. They demonstrated that an increase in $\mathrm{G}^{\prime}$ for mixtures of commercial xanthan with KGM at $\mathrm{pH}$ values of 4.5 and 4.25 occurs in two discrete steps on cooling. The first occurs at the temperature observed here for the same mixtures at neutral $\mathrm{pH}$ and the second occurs over the lower temperature range observed here for mixtures of KGM with pyruvate free xanthan.

They conclude that these two "waves" of gel formation are attributed to the interaction of KGM with, respectively, xanthan sequences that had retained a high content of pyruvate substituents, and sequences depleted in pyruvate by acid hydrolysis. They also reported that the increases in $\mathrm{G}^{\prime}$ were not dependent on the xanthan transition temperature.

Figures $6 \mathrm{a}$ and $\mathrm{b}$ show the temperature sweeps for xanthan samples on cooling. High pyruvate xanthan samples have one strong ascending wave at $\sim 60^{\circ} \mathrm{C}$ (Type B); the low pyruvate xanthans show one wave at $\sim 45^{\circ} \mathrm{C}$ (Type A) and SA/SP has both types A and B. However, $\mathrm{pH}$ was not varied here in contrast with the work of Agoub et al. (2007) ${ }^{30}$. Similar to the effect of increased salt levels, increasing the acidity which is equivalent to an increase in proton ion concentration, reduces the charge on the pyruvate and consequently increases the temperature of the conformational transition of xanthan. However the temperature of the interaction endotherm decreases.

What has not been reported (Agoub et al., 2007) ${ }^{30}$ is the result of the first heating of the samples, i.e. mixing the polymers cold and loading them cold into the rheometer. As can be seen on Figure 7a, the modulus for all xanthan samples during the first heat, shows both types of waves of increase but with different intensities. Linearizing the logarithmic scale for the modulus facilitates the comparison of the magnitude of the waves.

\section{The Effect of heat treatment and xanthan transition temperature on the interaction mechanism}

Figure $7 \mathrm{a}$ and $7 \mathrm{~b}$, for a high pyruvate sample in which the xanthan disorder-order transition temperature is below $60^{\circ} \mathrm{C}$ show a significant increase in the Type B interaction after the first heating (Figure $7 \mathrm{~b}$ ). Heating intensifies type $\mathrm{B}$ interactions and provides new opportunities for the formation of xanthan-co-synergist networks which may lead to a 
more unified network arrangement on cooling. Interestingly, after the first heat, the samples in which the xanthan helix-coil transition temperatures were higher than $\sim 60^{\circ} \mathrm{C}$ (Type B interaction occurs at $\sim 60^{\circ} \mathrm{C}$ ), e.g. SA/LP, no longer exhibit a type B wave or drop in the modulus at around $50^{\circ} \mathrm{C}$ with heating. Only the SA/SP-KGM mixture shows both types of interactions on cooling. This behaviour has already been explained by the temperature at which the helix to coil transition is found. As can be seen on Figure 1, the SA/SP xanthan disorder-order transition has started just before the Type B interaction temperature $\left(\sim 60^{\circ} \mathrm{C}\right)$ and has ended after it. At the point of the first wave of $\mathrm{G}^{\prime}$ increase $\left(60^{\circ} \mathrm{C}\right)$ some of the xanthan molecules are ordered. Therefore on cooling the xanthan in this sample can participate in both types of interactions.

\section{Verifying the proposed model}

In order to verify the proposed model of A and B type interactions, the transition temperature for SA/HP was adjusted by changing the salt content so that the mid-point occurred at the same temperature as the SA/SP sample i.e. the transition started below and finished above $60^{\circ} \mathrm{C}$ (Figure $8 \mathrm{a}$ and $\mathrm{b}$ ).

The SA/HP-KGM mixture in $15 \mathrm{mM} \mathrm{NaCl}$ shows both types of interaction on cooling comparable to the SA/SPKGM mixture.

On increasing the salt level to $40 \mathrm{mM} \mathrm{NaCl}$, the preferred interaction is Type A mechanism, especially after the first heat (Figure 6b). Williams et al. (1991) ${ }^{22}$ suggested that disordered xanthan interacts with KGM at very low ionic strength and by increasing the ionic strength to $40 \mathrm{mM}$ the interaction occurs only with ordered xanthan. Figure 8c compares the DSC curve for SA/HP-KGM mixture at $0.5 \%$ and $1 \%$ total polymer concentration, on cooling. As can be seen at $1 \%$ wt. the low temperature peak $\sim 45^{\circ} \mathrm{C}$ is detectable and represents Type A interactions. However, at this polymer concentration and ionic environment there is also evidence of a small amount of Type B interaction, with the additional higher temperature transition being that of the xanthan coil-helix transition.

As a further test, and using a different approach, $40 \mathrm{mM} \mathrm{NaCl}$ has been added after preheating a mixture of xanthan $\mathrm{SA} / \mathrm{HP}+\mathrm{KGM}$ at $45^{\circ} \mathrm{C}$ before letting the mixture cool. After adding salt at $45^{\circ} \mathrm{C}$, the cooled mixture was loaded on the rheometer and a temperature sweep performed (Figure 8d). At the temperature of salt addition, a gel due to the type A interaction would have been melted but that due to a type B interaction would be stable. Consequently the salt did not have an effect on the type B transition. After cooling and upon first heating the mixture shows the evidence of both Type A and B interaction, however, after the first heating and melting of the gel due to the Type B interactions, the salt is now distributed in the solution and on cooling the Type B transition has disappeared and only the type A gel remains.

A summary of the different types of interaction are shown on figure 9.

\section{In conclusion}

The main conclusions for this investigation are as follows:

A new model for interaction of xanthan and KGM is proposed in which 2 possible interaction mechanisms may exist singly or together. In the Type A interaction, xanthan keeps its helical conformation and the formed gel melts in a lower temperature range of approximately $30-45^{\circ} \mathrm{C}$. The type B interaction occurs with xanthan in a disordered conformation and the formed gel melts at the higher temperature of approximately $60^{\circ} \mathrm{C}$. The xanthan transition temperature is the key parameter in determining the Type of interaction (Figure 9) and can be manipulated by changing environmental conditions such as ionic concentration, $\mathrm{pH}$ and functional group content.

Part of the research leading to these results (AA) as funded by the European Community's Seventh Framework Program (FP7/2007-2013) under Grant Agreement No. 214015. We would like to thank Dr. G. Sworn, Mr. Emanuel Kerdavid and Mr. Jose Fayos of the Dupont Company for preparing, characterizing and providing the xanthan samples.

\section{REFERENCES}


(1) Ross-Murphy, S. B., Morris, V. J., \& Morris, E. R. In Faraday Symp. Chem. Soc. 1983 (Vol. 18, pp. 115-129). The Royal Society of Chemistry.

(2) Morris, E. R., Rees, D. A., Young, G., Walkinshaw, M. D., \& Darke, A. J. Mol. Biol. 1977, 110(1), 1-16.

(3) Dea, I., Morris, E. R., Rees, D. A., Welsh, E. J., Barnes, H. A., \& Price, J. Carbohydr. Res. 1977, 57, 249-272.

(4) Mannion, R. O., Melia, C. D., Launay, B., Cuvelier, G., Hill, S. E., Harding, S. E., \& Mitchell, J. R. Carbohy. polym. 1992, 19(2), 91-97.

(5) Annable, P., Williams, P. A. \& Nishinari, K. Macromolecules 1994, 27, 42044211.

(6) Copetti, G., Grassi, M., Lapasin, R., \& Pricl, S. Glycoconjugate J. 1997, 14(8), 951-961

(7) Fitzsimons, S. M., Tobin, J. T., \& Morris, E. R. Food Hydrocolloids 2008, 22(1), 36-46.

(8) Tako, M., \& Nakamura, S. FEBS letters 1986, 204(1), 33-36.

(9) Kitamura, S., Takeo, K., Kuge, T., \& Stokke, B. T. Biopolymers 1991, 31(11), 1243-55.

(10) Paradossi, G., Chiessi, E., Barbiroli, A., \& Fessas, D. Biomacromolecules 2002, 3(3), 498-504.

(11) Cairns, P., Morris, V.J., Miles, M.J., \& Brownsey, G.J. Food Hydrocolloids 1986, 1(1), 89-93.

(12) Cairns, P., Miles, M. J., Morris, V. J., \& Brownsey, G. J. Carbohy. Res. 1987,

(13) Brownsey, G. J., Cairns, P., Miles, M. J., \& Morris, V. J. Carbohydr. Res. 1988, 176, 329-334.

(14) Cheetham, N., \& Mashimba, E. Carbohydr. Polym. 1988, 9(3), 195-212.

(15) Morris, V. J. In G. O. Phillips, P. A. Williams, \& D. J. Wedlock (Ed.). Gums Stab. Food Ind. 6, [Proc. Int. Conf.], 6th 1992, (pp. 161-171). Oxford, UK: IRL Press.

(16) Morris, V. J., Brownsey, G. J., \& Ridout, M. J. Carbohy. Polym. 1994, 23(2), 139-140.

(17) Norton, I. T., Goodall, D. M., Frangou, S. A., Morris, E. R., \& Rees, D. A. J. Mol. Biol. 1984, 175(3), 371-394.

(18) Zhan, D. F., Ridout, M. J., Brownsey, G. J., \& Morris, V. J. Carbohy. polym. 1993, 21(1), 53-58

(19) Goycoolea, F. M., Foster, T. J., Richardson, R. K., Morris, E. R., \& Gidley, M. J. In G. O. Phillips, D. J. Wedlock, \& P. A. Williams (Eds.), Gums Stab. Food Ind. 7, [Proc. Int. Conf.], 7th 1994, (pp. 333-344). Oxford: IRL Press.

(20) Goycoolea, F. M. A, Richardson, R. K., Morris, E. R., \& Gidley, M. J. Macromolecules 1995, 28(24), 8308-8320

(21) Foster, T. J., \& Morris, E. R. In G. O. Phillips, D. J. Wedlock, \& P. A. Williams (Eds.), Gums Stab. Food Ind. 7, [Proc. Int. Conf.], 7th 1994, (pp. 281289). Oxford: IRL Press.

(22) Williams, P. a, Day, D. H., Langdon, M. J., Phillips, G. O., \& Nishinari, K. Food Hydrocolloids 1991, 4(6), 489-493.

(23) Lundin, L., \& Hermansson, A. M. Carbohy. polym. 1995, 26(2), 129-140. 
(24) Rinaudo, M., Milas, M., Bresolin, T., \& Ganter, J. L. M. S. In Macromol. Symp. 1999, (Vol. 140, No. 1, pp. 115-124). WILEY-VCH Verlag GmbH \& Co. KGaA.

(25) Goycoolea, F. M., Milas, M., \& Rinaudo, M. Int. J. Biol. Macromol. 2001, 29(3), 181-192.

(26) Abbaszadeh, A., Lad, M., Janin, M., Morris, G. A., MacNaughtan, W., Sworn, G., \& Foster, T. J. Food Hydrocolloids 2015, 44, 162-171.

(27) Shatwell, K. P., Sutherland, I W, \& Ross-Murphy, S. B. Int. J. Biol. Macromol. 1990 a, 12(2), 71-8.

(28) Chandrasekaran, R., \& Radha, A. (1997). Molecular modeling of xanthan: galactomannan interactions. Carbohydrate Polymers, 32(3-4), 201-208.

(29) Millane, R., \& Wang, B. Carbohy. Polym. 1990, 13(1), 57-68.

(30) Agoub, A. A., Smith, A. M., Giannouli, P., Richardson, R. K., \& Morris, E. R. Carbohydr. Polym. 2012, 69(4), 713-724. 


\title{
New Insights into Xanthan Synergistic Interactions with Konjac glucomannan: A Novel Interaction Mechanism proposal
}

\author{
A. Abbaszadeh ${ }^{1}$, W. MacNaughtan ${ }^{1}$, G. Sworn ${ }^{2}$ and T.J. Foster ${ }^{1}$ \\ ${ }^{1}$ Division of Food Sciences, School of Biosciences, University of Nottingham, Sutton Bonington Campus, \\ Loughborough, LE12 5RD, UK. \\ Member of the European Polysaccharide Network of Excellence (EPNOE). \\ ${ }^{2}$ DuPont, Danisco France SAS, 20 rue Brunel, 75017 Paris, France.
}

Keywords: Xanthan; Konjac mannan; Helix, Random Coil, Models of Interaction

\section{Tables}




\begin{tabular}{|c|c|c|c|}
\hline Xanthan & Abbreviation & Acetate $(\%)$ & Pyruvate $(\%)$ \\
\hline Standard Acetate(SA) Standard Pyruvate(SP) & $\mathrm{SA} / \mathrm{SP}$ & 6.19 & 3.85 \\
\hline Standard Acetate(SA) Low Pyruvate (LP) & SA/LP & 6.02 & 2.20 \\
\hline $\begin{array}{c}\text { Standard Acetate(SA) Very Low } \\
\text { Pyruvate(VLP) }\end{array}$ & SA/VLP & 5.60 & 0.50 \\
\hline Standard Acetate(SA) High Pyruvate (HP) & $\mathrm{SA} / \mathrm{HP}$ & 5.10 & 6.49 \\
\hline Low Acetate(LA) High Pyruvate (HP) & $\mathrm{LA} / \mathrm{HP}$ & 1.46 & 6.54 \\
\hline Very Low Acetate(VLA) High Pyruvate (HP) & VLA/HP & 0.51 & 6.98 \\
\hline $\begin{array}{l}\text { Very Low Acetate(VLA) Standard Pyruvate } \\
\text { (SP) }\end{array}$ & VLA/SP & - & - \\
\hline
\end{tabular}

Table 1 The acetate and pyruvate levels in the xanthan samples used in this study together with the abbreviations used in the text. 


\title{
New Insights into Xanthan Synergistic Interactions with Konjac glucomannan: A Novel Interaction Mechanism proposal
}

\author{
A. Abbaszadeh ${ }^{1 *}$, W. MacNaughtan ${ }^{1}$, G. Sworn ${ }^{2}$ and T.J. Foster ${ }^{1}$ \\ ${ }^{1}$ Division of Food Sciences, School of Biosciences, University of Nottingham, Sutton Bonington Campus, \\ Loughborough, LE12 5RD, UK. \\ Member of the European Polysaccharide Network of Excellence (EPNOE). \\ ${ }^{2}$ DuPont, Danisco France SAS, 20 rue Brunel, 75017 Paris, France.
}

Keywords: Xanthan; Konjac mannan; Helix, Random Coil, Models of Interaction

\section{Figures}

*Corresponding author: abaszadeh@hotmail.com 
[Type text]

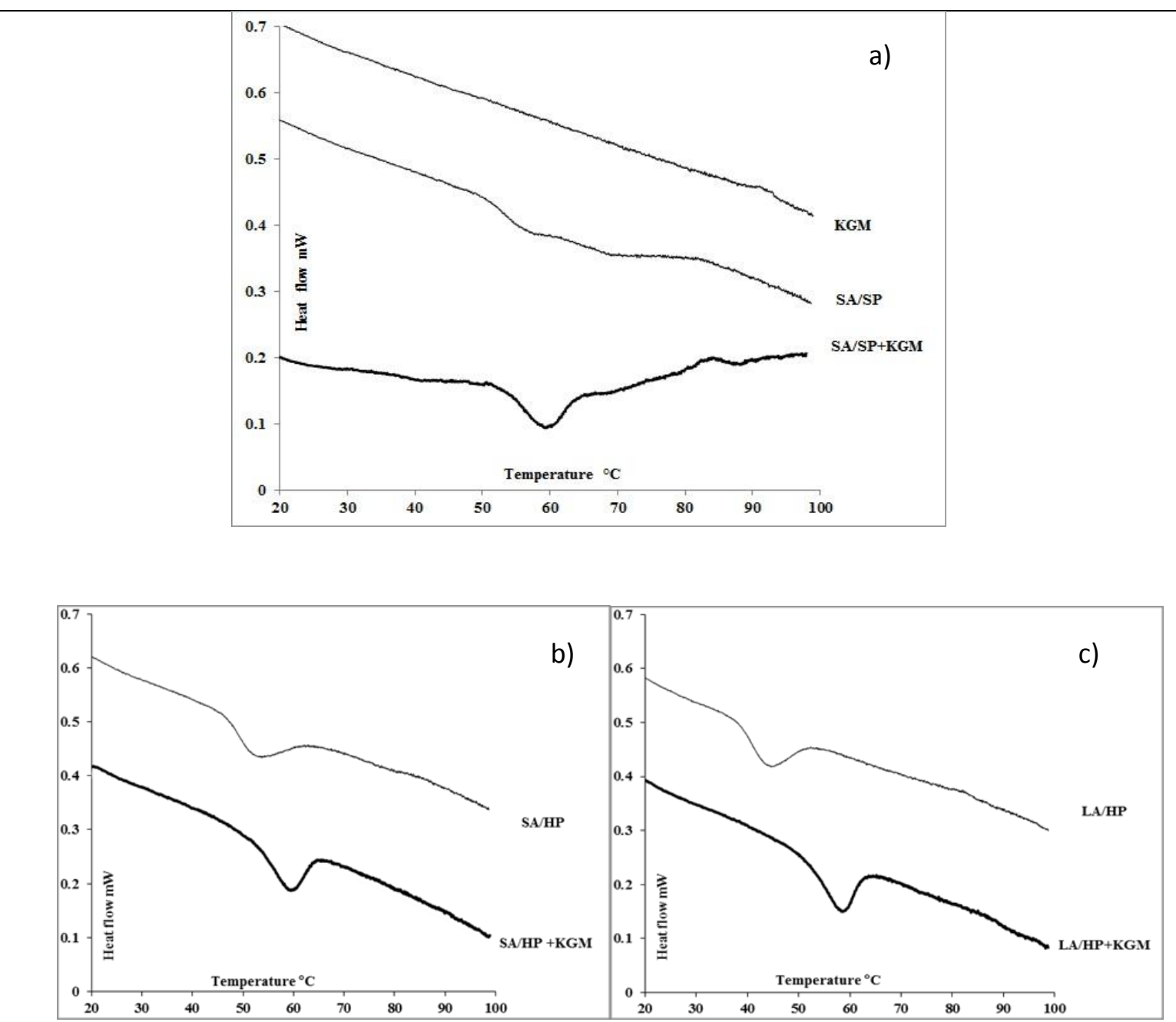

Figure 1 DSC 2nd Heats at a scan rate of $1^{\circ} \mathrm{C}_{\mathrm{min}^{-1}}$ for a) SA/SP b) SA/HP and c) LA/HP xanthan both alone and in 1:1 mixtures with KGM at an ionic strength of $10 \mathrm{mM}$ $\mathrm{NaCl}$ and a total concentration of $0.5 \%$. 
[Type text]
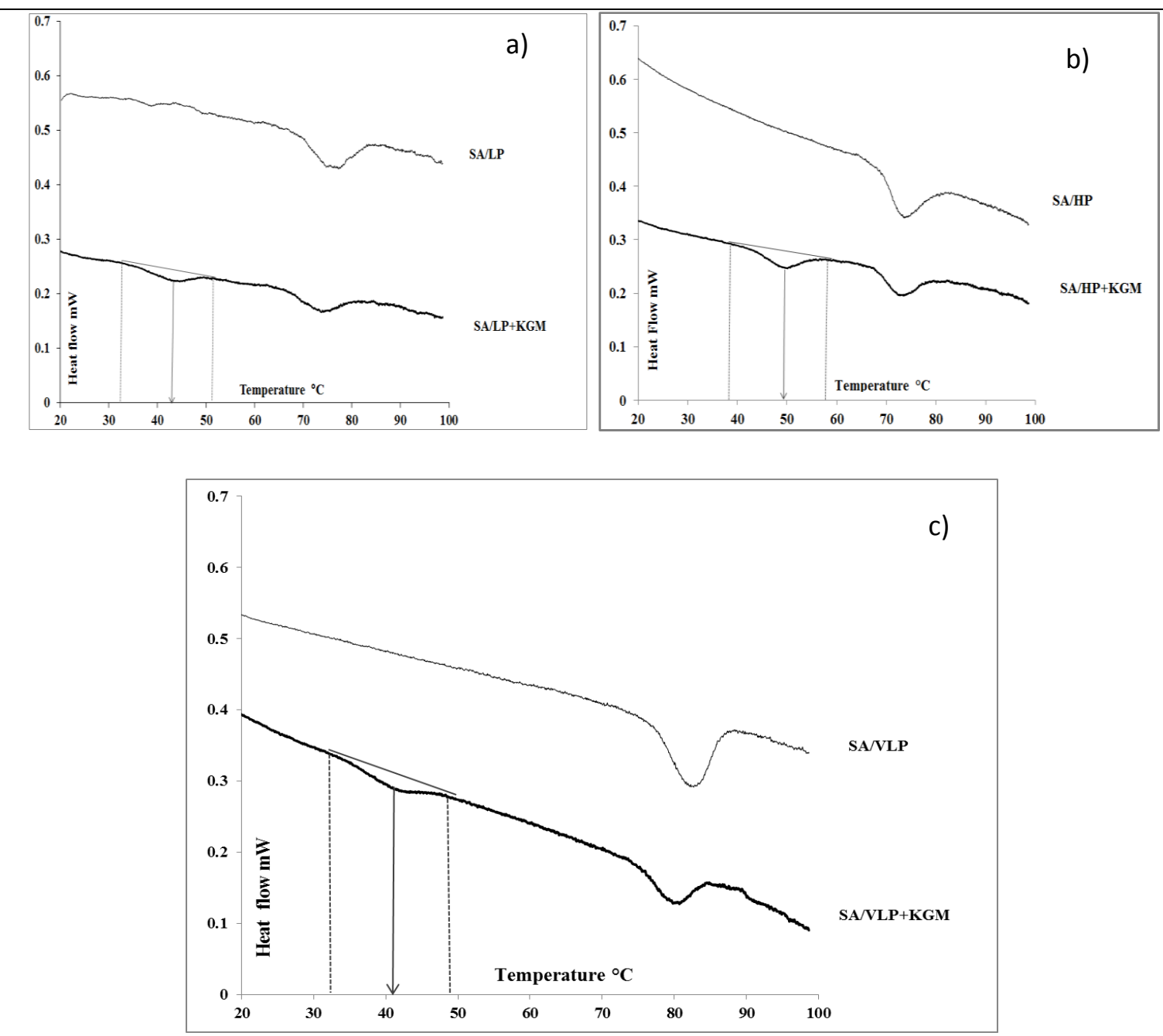

Figure 2 DSC 2nd Heats at a scan rate of $1^{\circ} \mathrm{C} \mathrm{min}^{-1}$ for a) SA/LP xanthan at an ionic strength of $10 \mathrm{mM} \mathrm{NaCl} \mathrm{b)} \mathrm{SA/HP} \mathrm{xanthan} \mathrm{at} \mathrm{an} \mathrm{ionic} \mathrm{strength} \mathrm{of} 40 \mathrm{mM} \mathrm{NaCl} \mathrm{c)}$ SA/VLP xanthan at an ionic strength of $40 \mathrm{mM} \mathrm{NaCl}$; both alone and in 1:1 mixtures with KGM at a total concentration of 0.5\%.The peak and limiting temperatures of the synergistic interaction peak are shown by arrows and dotted lines respectively. 
[Type text]

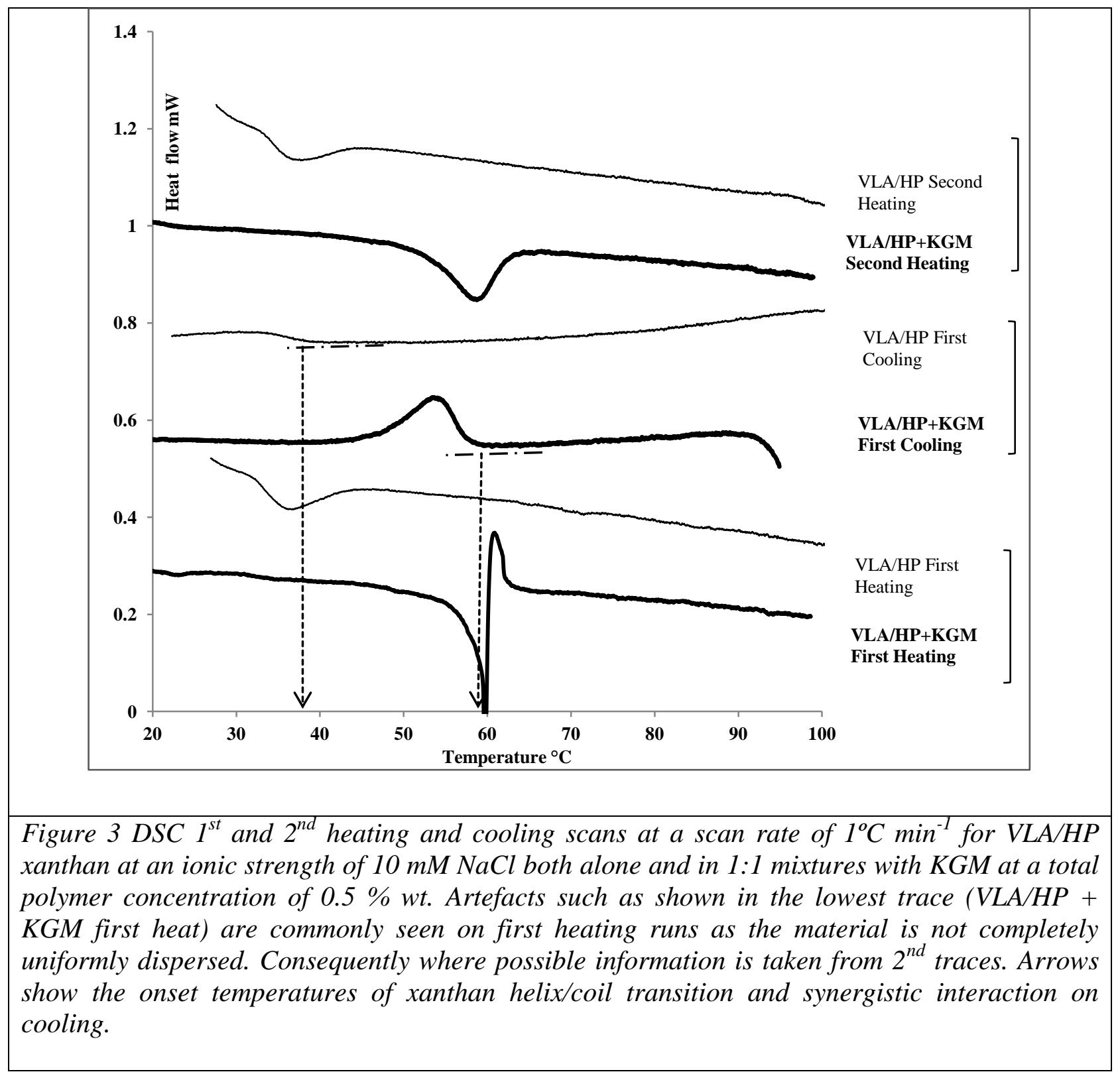


[Type text]

a)

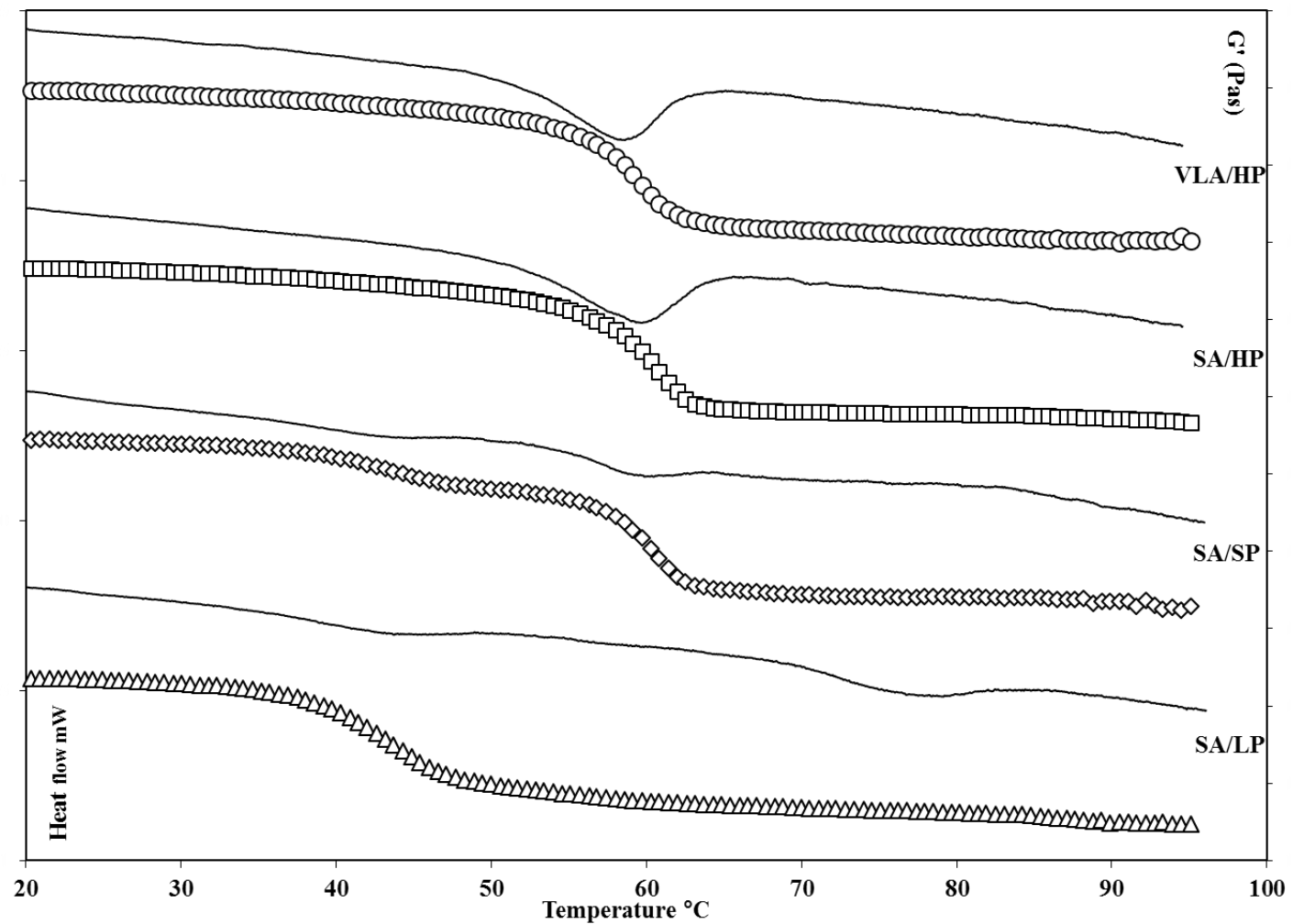

b)

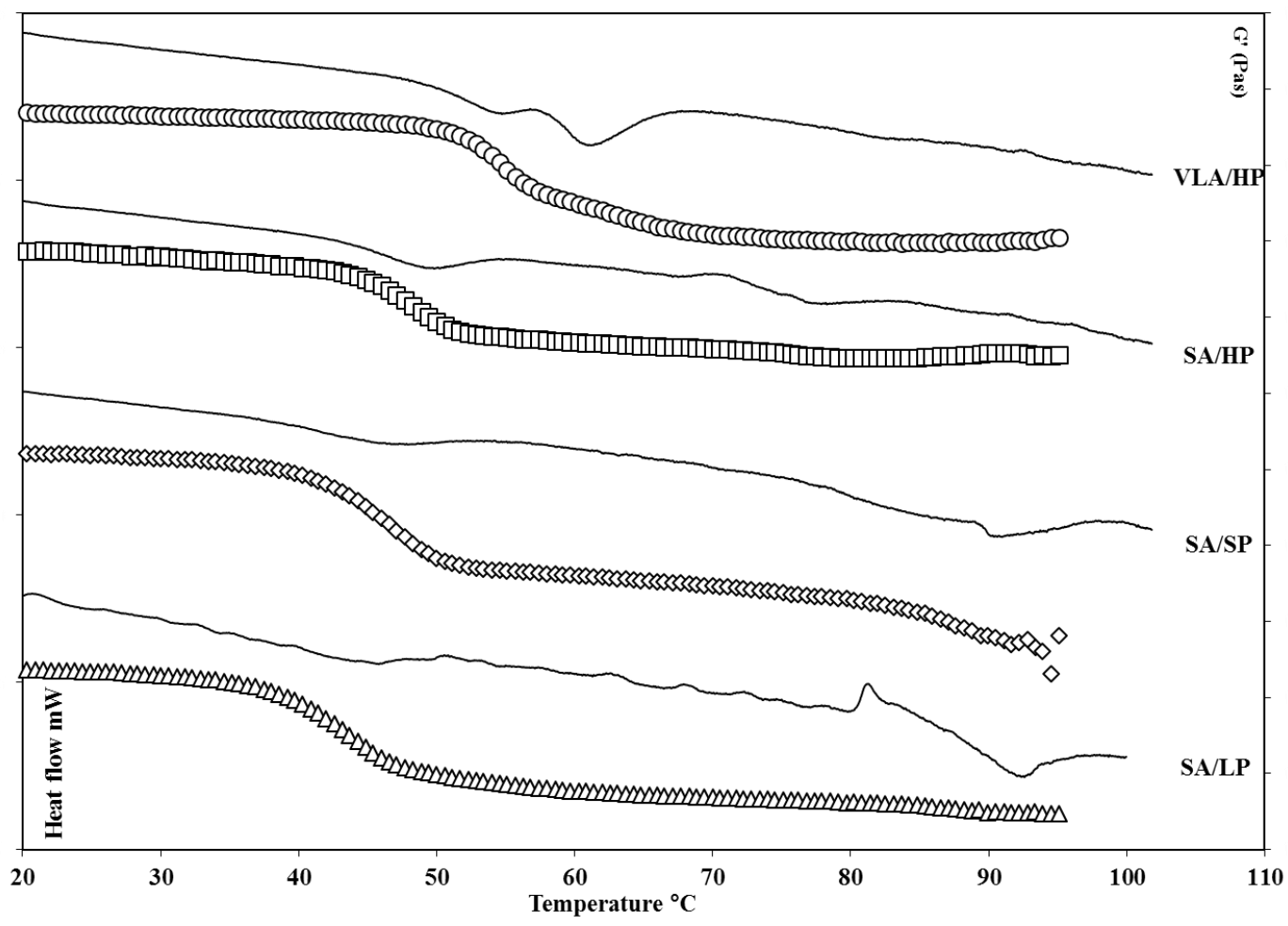


Figure $4 G^{\prime}$ for the 2nd heat of VLA/HP xanthan (०), SA/HP xanthan ( $\left.\square\right)$, SA/SP xanthan ( $\left.\diamond\right)$ and SA/LP xanthan $(\Delta)$ and corresponding DSC curves in 1:1 mixtures with KGM and at a total polymer concentration of $1 \%$ wt. at a) $10 \mathrm{mM} \mathrm{NaCl}$ and b) $40 \mathrm{mM} \mathrm{NaCl}$.

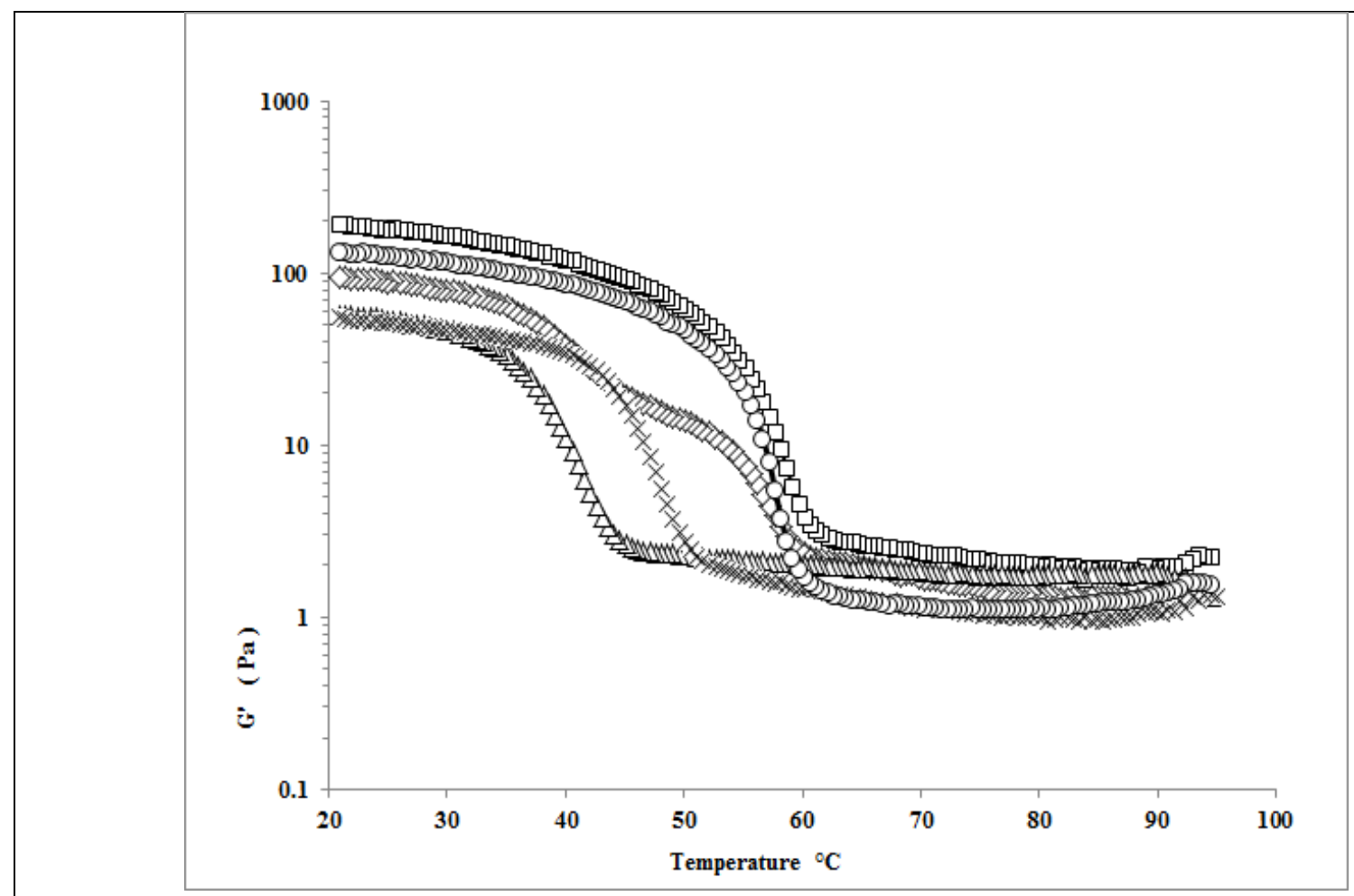

Figure $5 G^{\prime}$ on cooling for $S A / H P$ xanthan ( $\square$ ), LA/HP xanthan (०), SA/SP xanthan ( $\left.\diamond\right), S A / L P$ xanthan $(\Delta)$ all at $10 \mathrm{mM} \mathrm{NaCl}$ and $\mathrm{SA} / \mathrm{HP}$ xanthan $(X)$ at $40 \mathrm{mM} \mathrm{NaCl}$; in 1:1 mixtures with $K G M$ and at a total polymer concentration of $0.5 \%$. 
[Type text]

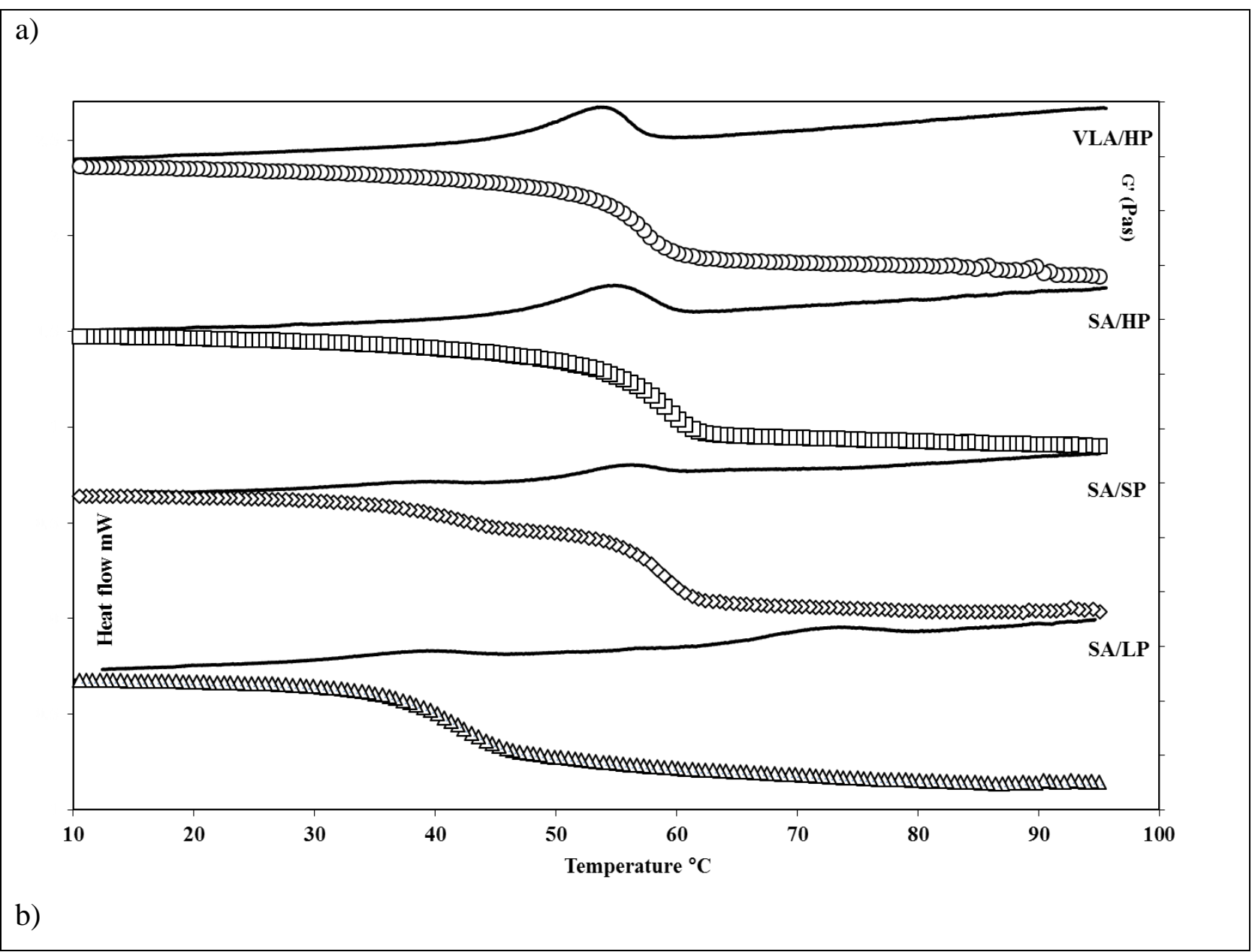


[Type text]

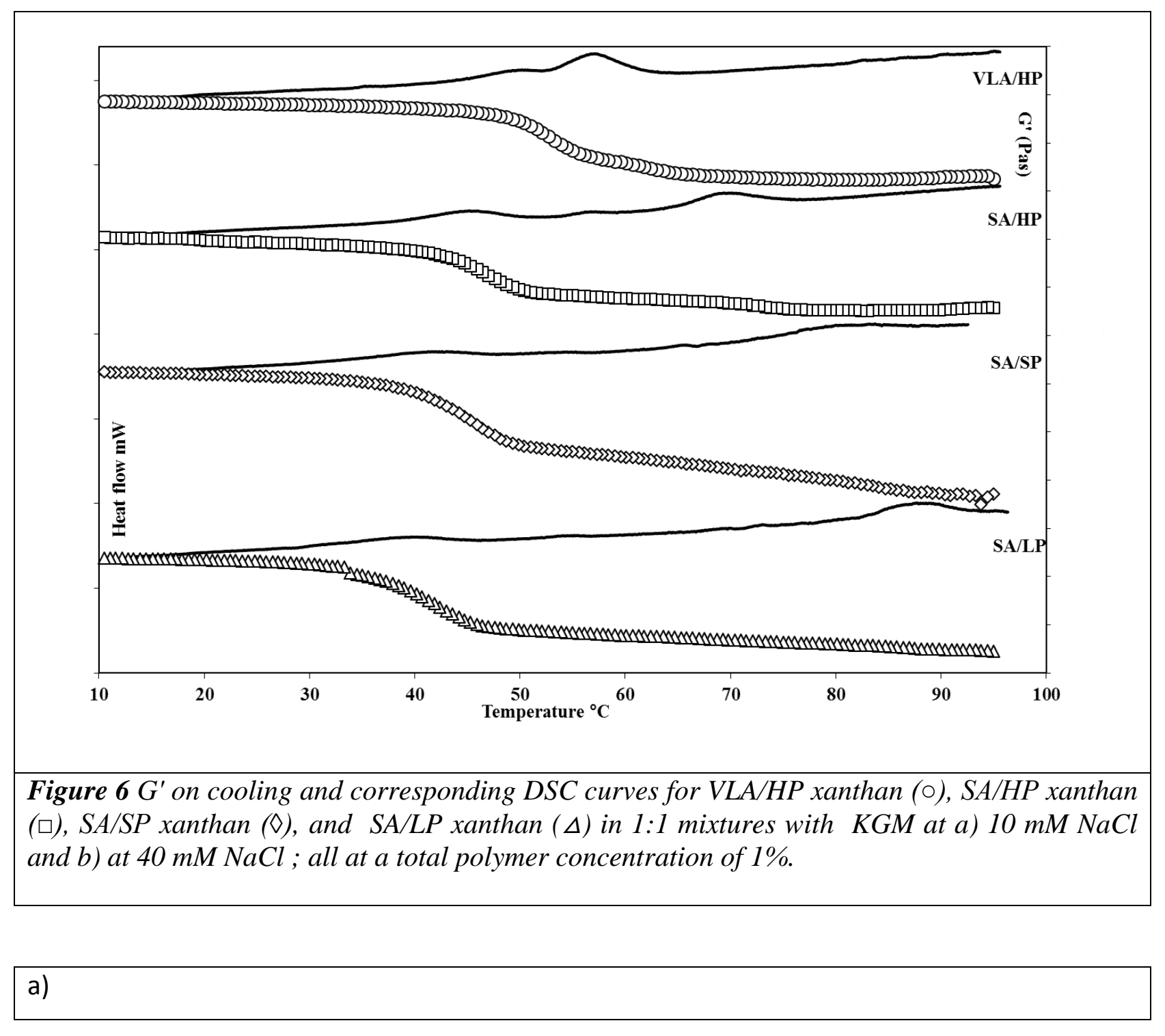


[Type text]

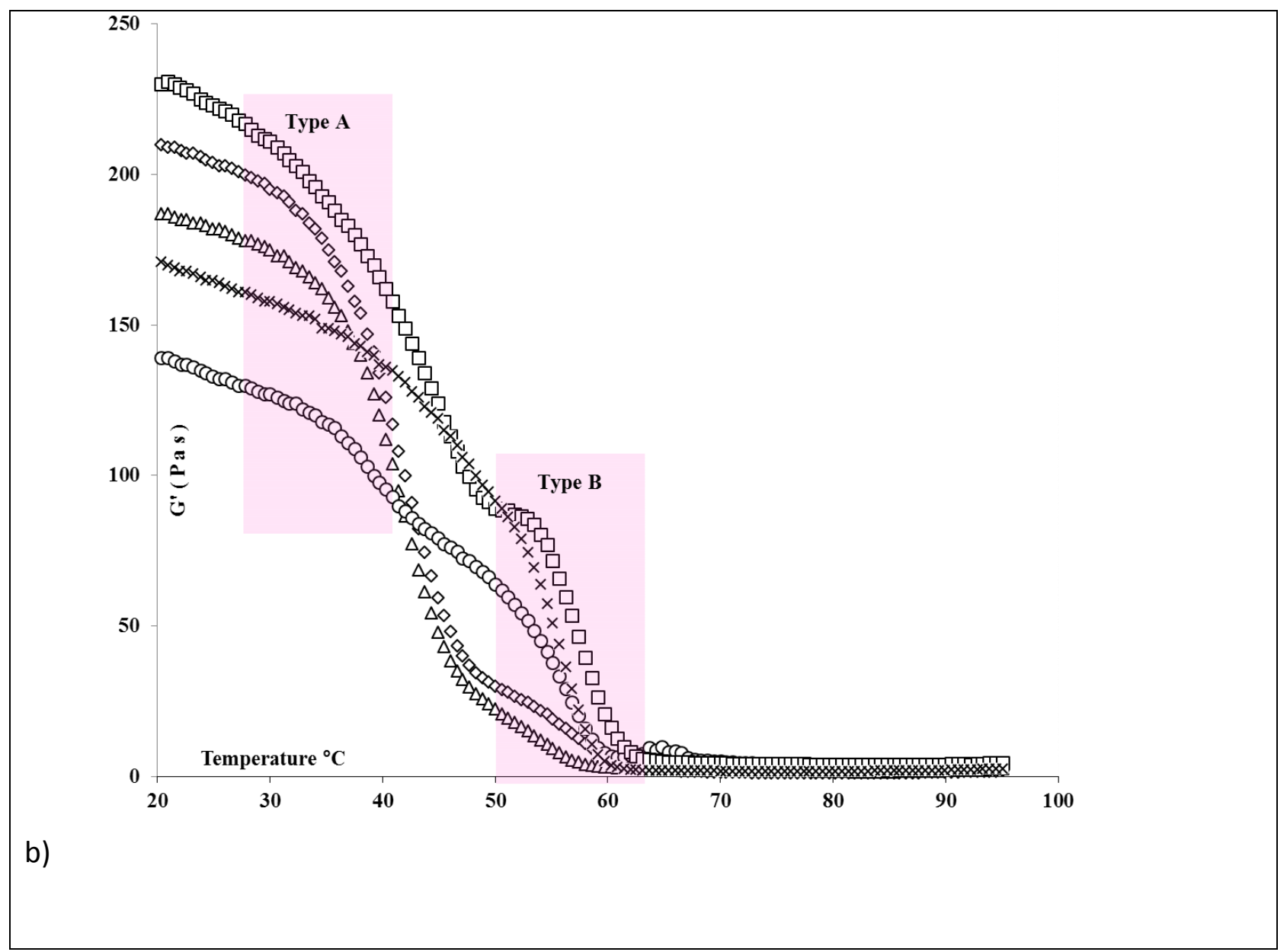


[Type text]

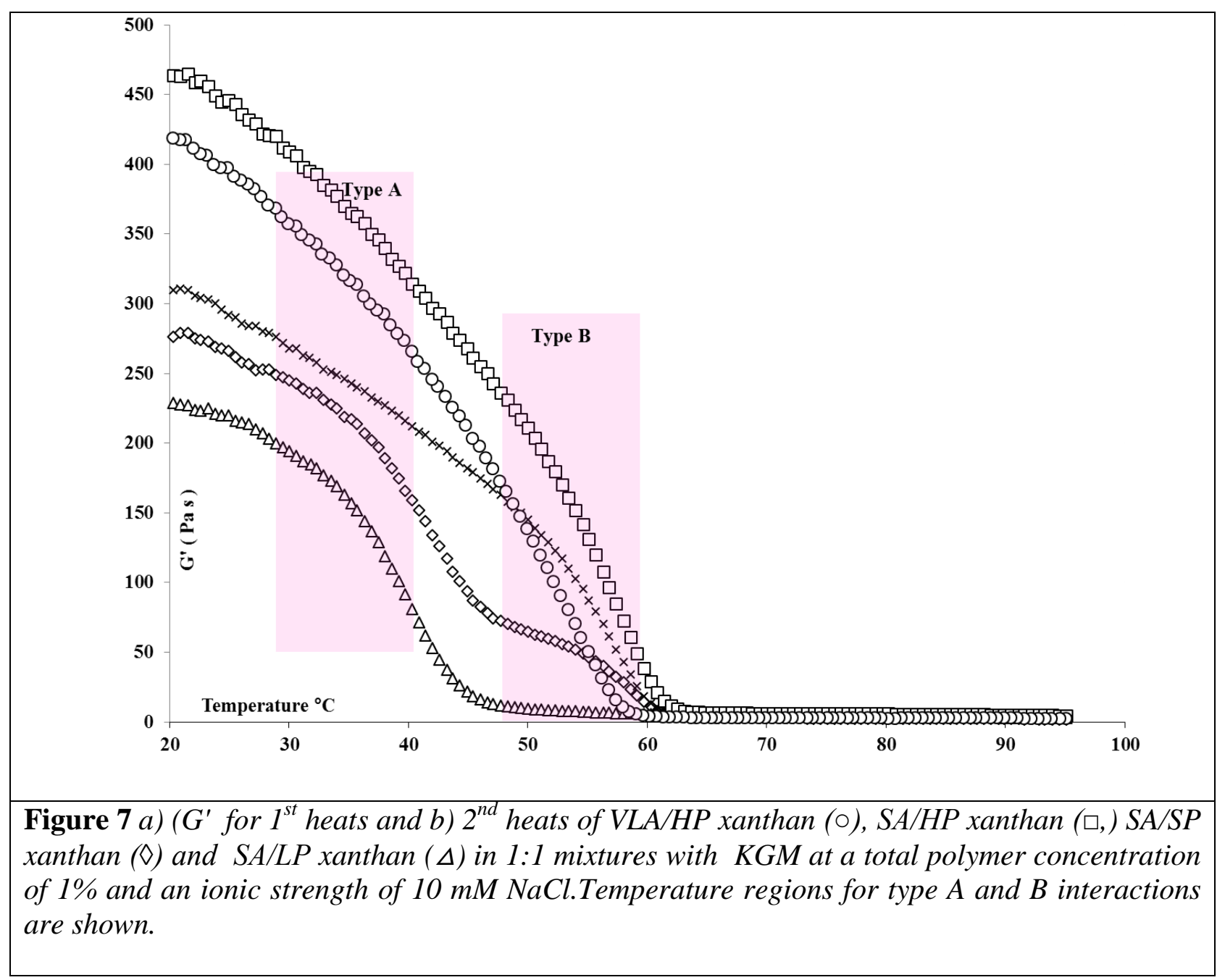

a) 
[Type text]

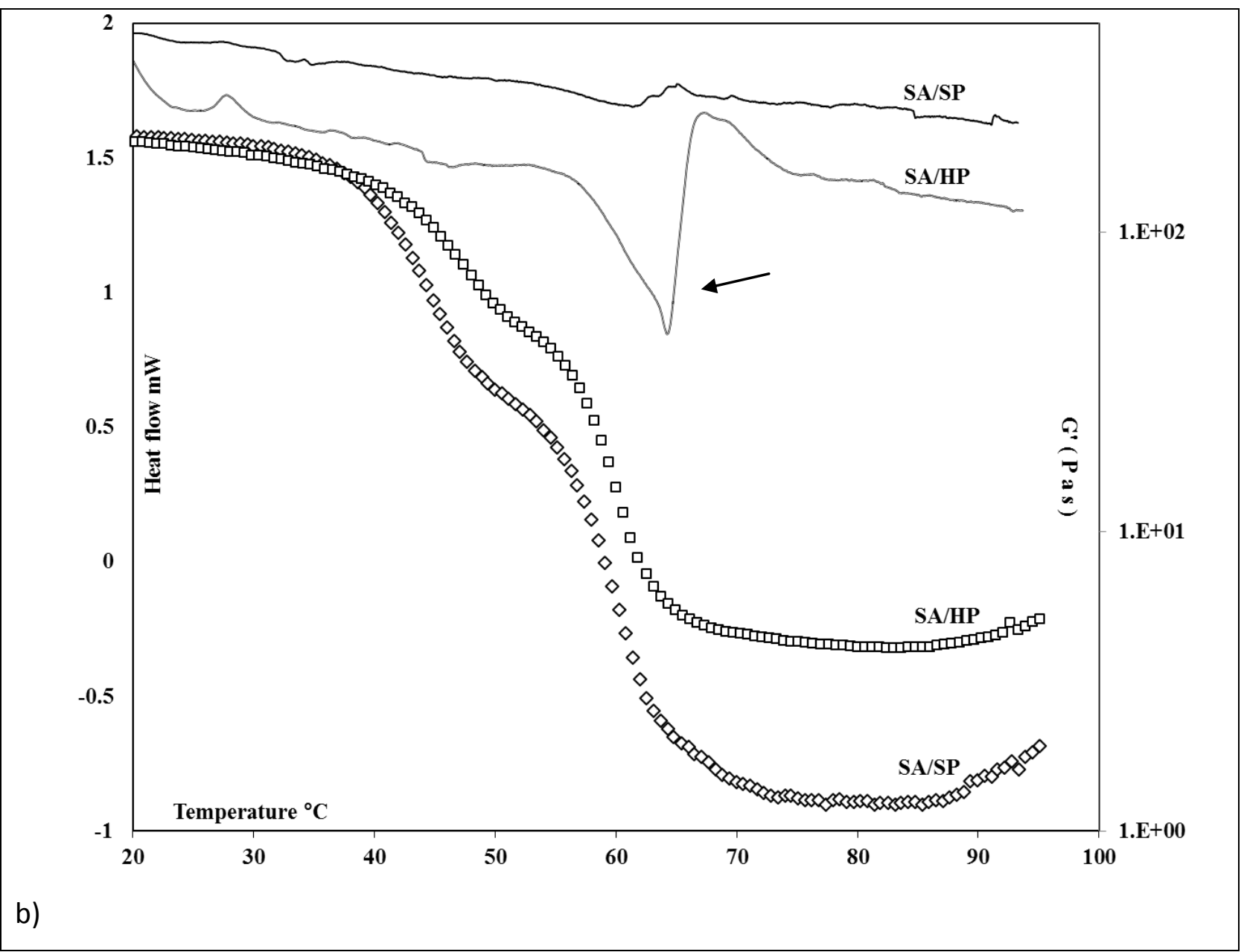


[Type text]

2

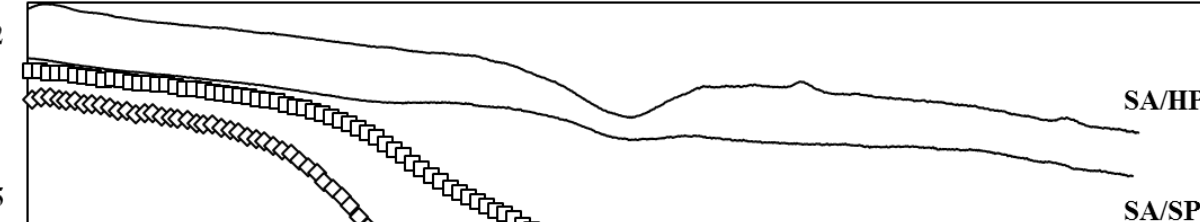

1

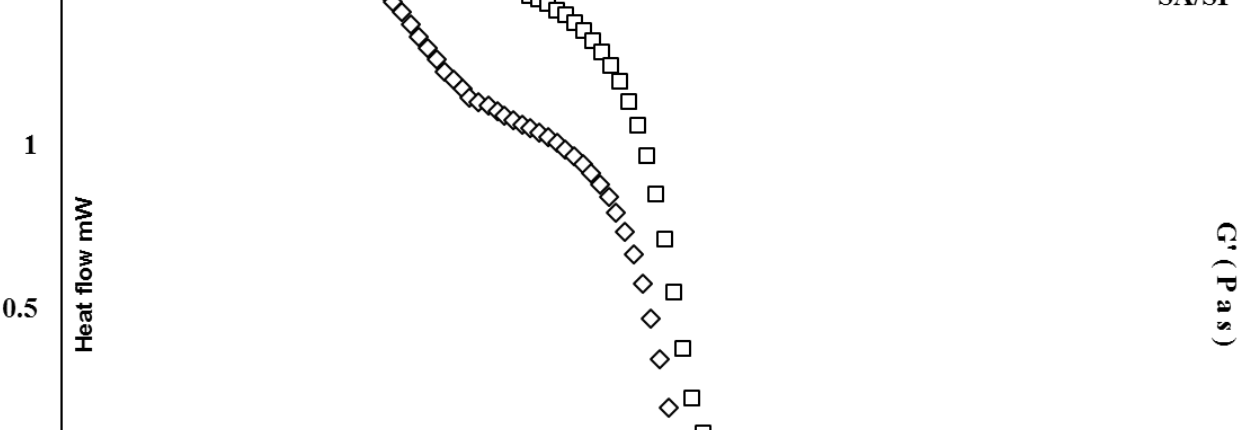

0

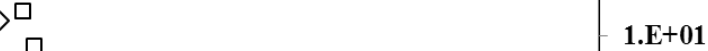

$-0.5$

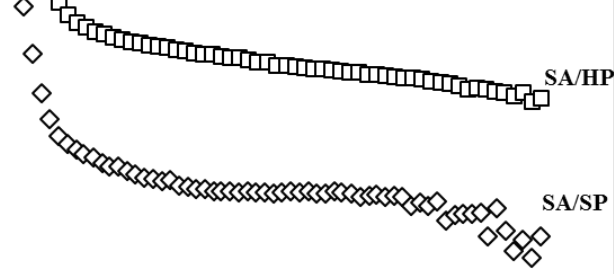

1.E+02

1.E+01

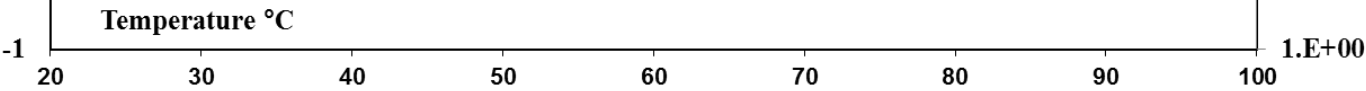

c)

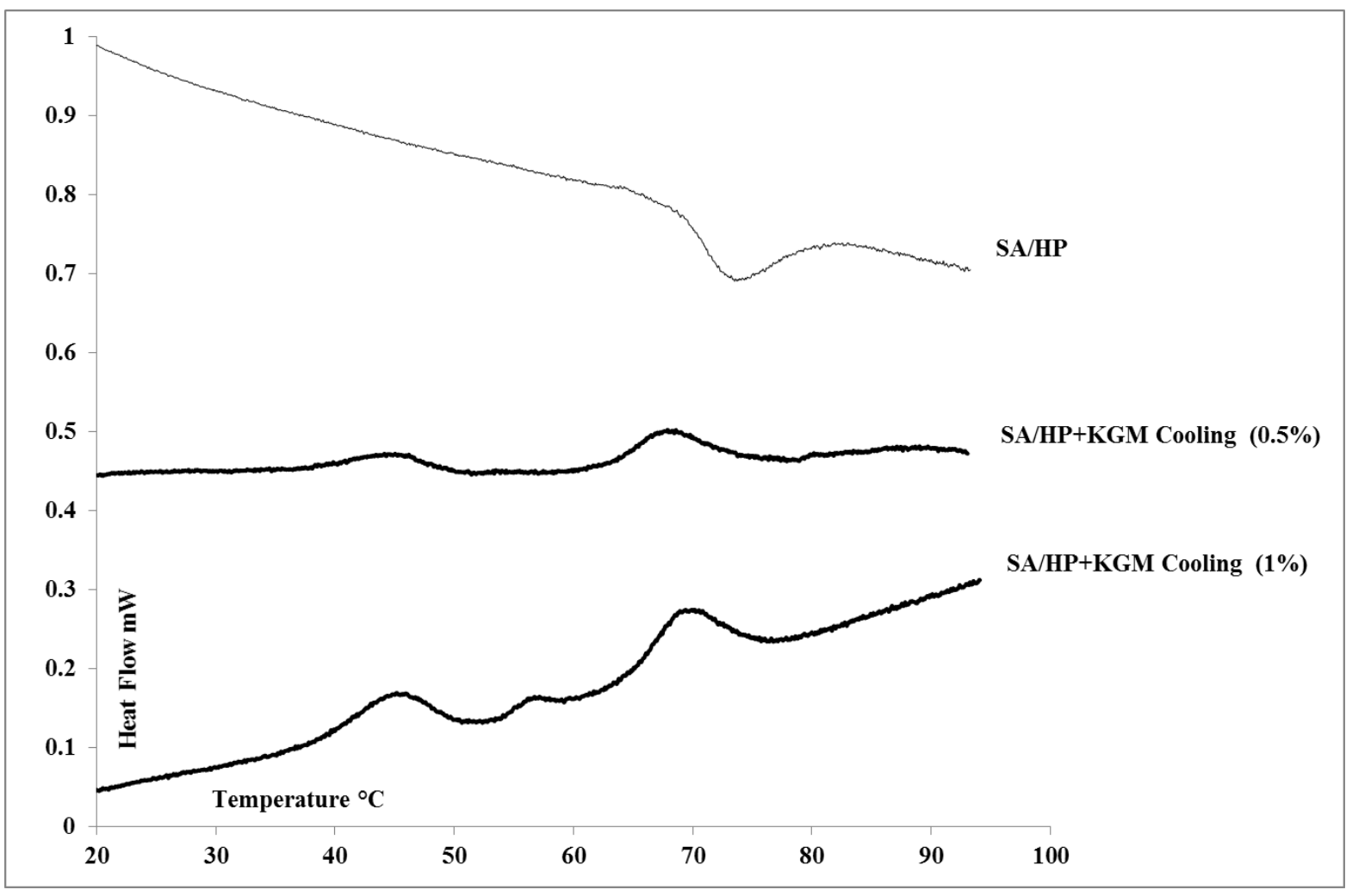


d)

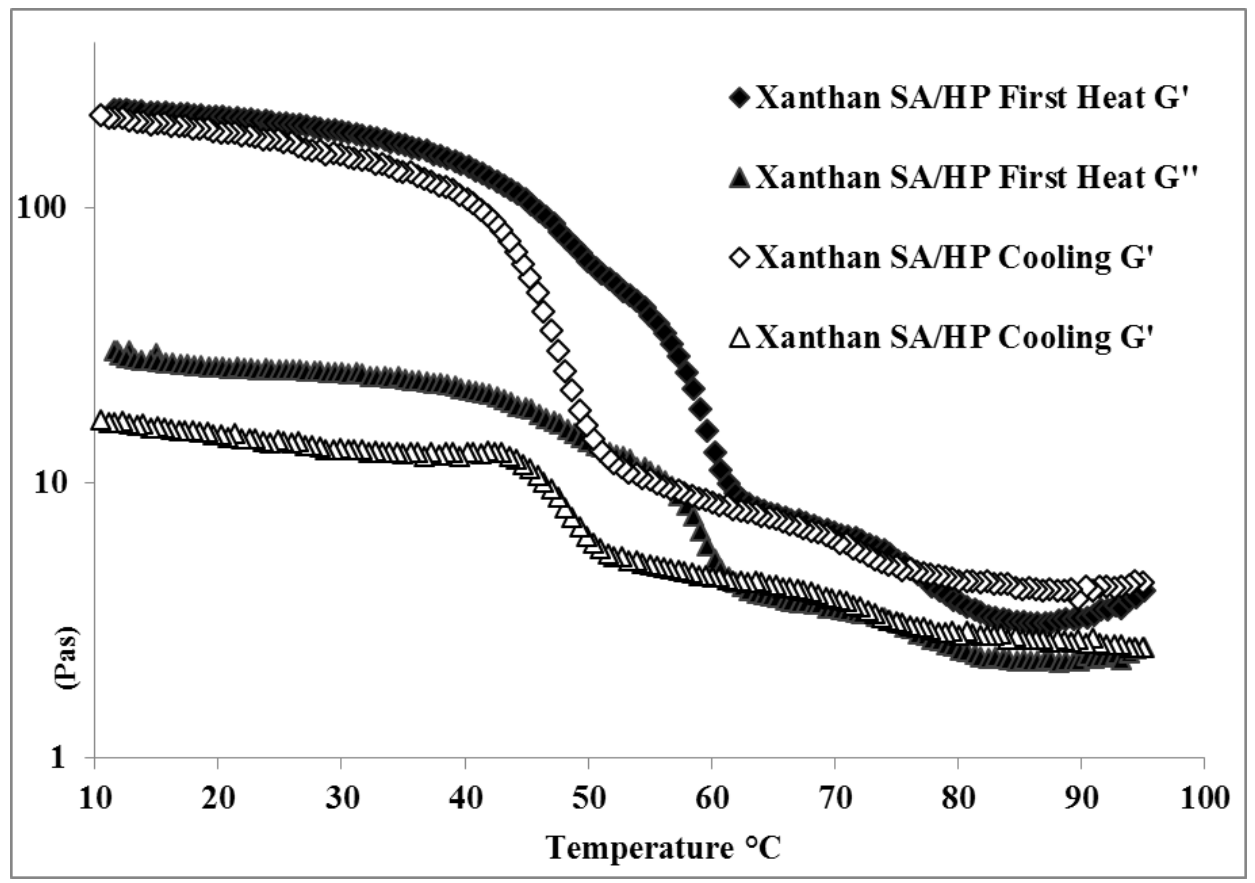

Figure 8 a) $\mathrm{G}^{\prime}$ for the $1^{\text {st }}$ heat and $b$ ) $2^{\text {nd }}$ heat of SA/HP xanthan in $15 \mathrm{mM} \mathrm{NaCl}(\square)$ and SA/SP xanthan in $10 \mathrm{mM} \mathrm{NaCl}(\diamond)$ both in 1:1 mixtures with KGM and at a total concentration of $1 \%$. Also shown are the corresponding DSC heat flow curves. DSC 1st heating traces can often show artefacts such as the jump marked here with an arrow and similar to that shown on figure 3. These can be due to non-uniform distribution, settling and convection in the DSC cell. c) Heating and cooling scans for SA/HP xanthan in $40 \mathrm{mM} \mathrm{NaCl}$ in 1:1 mixtures with KGM at total concentrations of 0.5 and $1 \%$. d) $1^{\text {st }}$ heating and cooling scans for SA/HP xanthan preheated at $45^{\circ} \mathrm{C}$ in $40 \mathrm{mM} \mathrm{NaCl}$ in 1:1 mixtures with KGM at a total concentration of $1 \%$.

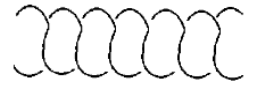

$\checkmark$

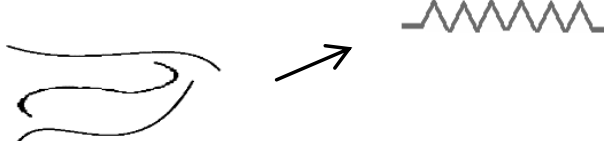

Xanthan

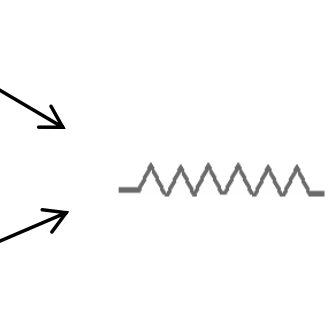

Konjac Glucomannan

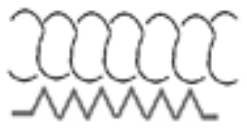

Type A
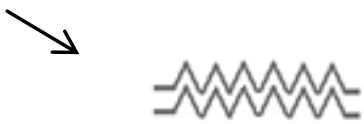

Type B

Junction Zone 
[Type text]

Figure 9 Proposed mechanisms for the interaction of xanthan with Konjac glucomannan. 